dans quelques mois, la Rivière Bleue n'existera plus. Une société industrielle puissante établit un barrage à Yaté, et capte les eaux de la Rivière Bleue et des rivières voisines. Un lac immense recouvrira la région, et les fougères en question seront à plus de $50 \mathrm{~m}$ sous l'eau. Désireux de récolter des exemplaires de cette espèce avant leur disparition, jai organisé une expédition de 3 jours - mon père, moi. un guide et 3 cheveaux. J'ai receuilli tout ce que jai pu trouver.....

\title{
XXXI. Ein neues Lepidium aus Persien.
}

Von A. Thellung (Zürich).

(Originaldiagnose)

Lepidium Bornmuelleranum ${ }^{1)}$ Thell., nov. spec.

Perenne, pumilum, concinnum. Radix crassa ( $\pm 5 \mathrm{~mm}$ diam.), verticalis, pluricaulis, collo rudimentis fibrosis foliorum delapsorum vestita. Caules $3-6$, ex axillis foliorum basilarium vel eorum rudimentorum enati, decumbenti-ascendentes, $7-10 \mathrm{~cm}$ longi, valde flexuosi, foliati, plerumque a medio divaricato-ramosi, leviter angulosi, per totam longitudinem pilis gracilibus recurvatis acutis breviter hirsutuli et insuper superne pilis claviformibus obtusis obsiti, ut rami in racemos terminales ca. 15-25floros abeuntes. Folia crasso-coriacea, pilis eis caulis similibus remote pubescentia; basilaria longe petiolata petiolis gracilibus superne canaliculatis ciliatis basi vaginantim dilatatis, lamina parva ( $\pm 1 \mathrm{~cm}$ longa et lata) late ovata (longitudine haud raro latiore) basi subito contracta, saepius acutiuscula, basi interdum lobulis utrinque 1-2 parvis rotundatis lyrato-pinnatifida, ceterum integerrima; folia caulina inferiora basilaribus similia, sed minus longe petiolata; media et superiora $\pm 1 \mathrm{~cm}$ longa (ramalia minora), spathulato-oblanceolata,integerrima, basi satis lata exauriculata sessilia. Flores satis inconspicui; sepala $1 \mathrm{~mm}$ longa, ovato-elliptica, violaceo-rubella, anguste albo-marginata, dorso pubescenti-hirsutula; petala obovato-spathulata, calyce $1 \frac{1}{2}$-plo longiora, in unguem satis latum et indistinctum sensim attenuata, alba; stamina $2+4$; glandulae 6 brevissimae (calycis vix $1 / 10$ longitudine attingentes) rotundato-ovatae. Racemi fructiferi breves et densi, axi et pedicellis pilis partim claviformibus hirtellis, pedicellis anguloso-compressis (dorsiventraliter \pm complanatis) arcuato-patentibus siliculae aequilongis. Silicula elliptica, $2^{1 / 2} \times 3^{1 / 2} \mathrm{~mm}$, utrinque obtusiuscula, apice anguste sed distincte alata et acute emar-

1) Ich dediziere diese zierliche Spezies Herrn J. Bornmüller in Weimar, dem bekannten, hochverdienten Erforscher der orientalischen Flora, dem ich fiir mancherlei wertvolle Dienstleistungen zu grossem Dank verpfliohtet bin. Bildung des adjektivischen Speziesnamens nach Empfoblung XI b) und d) der Internationalen Nomenklaturregeln (vergl. Carex Hallerana). 
ginata, stylo brevi (vix $1 / 3 \mathrm{~mm}$ ) ab alis libero emarginaturam haud vel vix superante; valvulae maturae reticulatae, inferne acute carinatae, fere a medio ad apicem sensim latius (apice ad $1 / 6-1 / 8$ longitudinis septi) alatae, lobulis alaribus porrectis obtusiusculis. Semina matura ignota.

Persia occid.: In $\mathrm{m}$. Kohrud (südlich von Teheran), versim. in locis salsis, leg. Th. Strauss, 10. Mai 1909. Typus in herb. Haussknecht et herb. Bornmüller.

Species affinis habitu, textura foliorum, indumento etc. $L$. carti. lagineo (J. Mayer) Thell., s. I. (incl. L. crassifolium W. K., L. pumilum Boiss. et Bal., L. caespitosum Desv. etc.), distincta tamen floribus multo minus conspicuis, petalis indistincte tantum unguiculatis, pedicellis brevioribus complanatis et praesertim silicula distincte alata et emarginata stylo haud vel vix exserto. A $L$. flexuoso Thunb. (Afr. austr.) quoque affini distinguitur floribus minus conspicuis, silicula emarginata, stylo brevi ab alis libero subincluso (nec $3 / 4 \mathrm{~mm}$ exserto).

In meiner monographischen Bearbeitung der Gattung Lepidium ${ }^{1}$ ) würde $L$. Bornmuelleranum im Bestimmungsschlüssel der altweltlichen Arten der Sektion Nasturtioides (S. 77-83) mit Rücksicht auf den nicht aus der Ausrandung vorragenden Griffel von $L$. cartilagineum und $L$. flexuosum weit getrennt in die - künstliche - Subsektion Dileptium gestellt werden müssen; die neue Art käme dort (S. 78) in die Nähe von $L$. subulatum und $L$. Cardamine zu stehen, von denen sie sich schon durch die kurzen Fruchtstiele und das Vorkommen von Keulenhaaren unterscheidet.

\section{Uber einige neue Ficus-Arten aus dem belgischen Kongo.}

Von E. De Wildeman.

(Originaldiagnosen.)

H. H. Dr. Mildbraed und N. Burret haben in Englers Bot. Jahrb., Bd. 46 (1911), eine Revision der afrikanischen Ficus-Arten publiziert. Wir glauben, dass diese Autoren in dieser Monographie zu viele Arten zusammengezogen haben.

Seit mehreren Jahren hatten wir Notizen gesammelt für eine monographische Studie afrikanischer Arten dieser Gattung, aber hatten die Gelegenheit nicht, diese Arbeit zu vervollständigen.

Da nun auch H. J. Hutchinson, aus Kew Herbarium, die Revision der Gattung Ficus für die Flora von Afrika arbeitet, sind unsere Studien ganz unnötig geworden und wir wollen hier nur die Diagnosen einiger Arten aus Kongo, das wir neu glauben, abgeben.

Wir hoffen, weiteres über diese Arten in den Abhandlungen vom Kongo-Museum, mit zahlreichen Abbildungen, publizieren zu können.

Brüssel, April 1913.

1) A. Thellung, Die Gattung Lepidium (L.) R. Br. Eine monographische Studie. - Neue Denkschr. d. schweiz. Ges. f. Naturw., Bd. XLI, Abh. 1 (1906). 